\title{
Brain activity patterns of phonemic representations are atypical in beginning readers with family risk for dyslexia
}

Citation for published version (APA):

Vandermosten, M., Correia, J., Vanderauwera, J., Wouters, J., Ghesquière, P., \& Bonte, M. (2020). Brain activity patterns of phonemic representations are atypical in beginning readers with family risk for dyslexia. Developmental Science, 23(1), [e12857]. https://doi.org/10.1111/desc.12857

Document status and date:

Published: 01/01/2020

DOI:

10.1111/desc. 12857

Document Version:

Publisher's PDF, also known as Version of record

Document license:

Taverne

Please check the document version of this publication:

- A submitted manuscript is the version of the article upon submission and before peer-review. There can be important differences between the submitted version and the official published version of record.

People interested in the research are advised to contact the author for the final version of the publication, or visit the DOI to the publisher's website.

- The final author version and the galley proof are versions of the publication after peer review.

- The final published version features the final layout of the paper including the volume, issue and page numbers.

Link to publication

\footnotetext{
General rights rights.

- You may freely distribute the URL identifying the publication in the public portal. please follow below link for the End User Agreement:

www.umlib.nl/taverne-license

Take down policy

If you believe that this document breaches copyright please contact us at:

repository@maastrichtuniversity.nl

providing details and we will investigate your claim.
}

Copyright and moral rights for the publications made accessible in the public portal are retained by the authors and/or other copyright owners and it is a condition of accessing publications that users recognise and abide by the legal requirements associated with these

- Users may download and print one copy of any publication from the public portal for the purpose of private study or research.

- You may not further distribute the material or use it for any profit-making activity or commercial gain

If the publication is distributed under the terms of Article $25 \mathrm{fa}$ of the Dutch Copyright Act, indicated by the "Taverne" license above, 


\title{
Brain activity patterns of phonemic representations are atypical in beginning readers with family risk for dyslexia
}

\author{
Maaike Vandermosten $^{1,2}$ | Joao Correia ${ }^{2,3}$ | Jolijn Vanderauwera ${ }^{1,4}$ | Jan Wouters ${ }^{1}$ | \\ Pol Ghesquière $^{4}$ | Milene Bonte ${ }^{2}$
}

\begin{abstract}
${ }^{1}$ Research Group ExpORL, Department of Neuroscience, KU Leuven, Leuven, Belgium

${ }^{2}$ Department of Cognitive Neuroscience and Maastricht Brain Imaging Center, Faculty of Psychology and Neuroscience, Maastricht University, Maastricht, The Netherlands

${ }^{3}$ Basque Center on Cognition, Brain and Language, San Sebastian, Spain

${ }^{4}$ Parenting and Special Education Research Unit, Faculty of Psychology and Educational Sciences, KU Leuven, Leuven, Belgium

\section{Correspondence}

Maaike Vandermosten, Herestraat 49 bus

721, 3000 Leuven, Belgium.

Email: Maaike.vandermosten@kuleuven.be

Funding information

Fonds Wetenschappelijk Onderzoek, Grant/ Award Number: G0920.12 and postdoctoral grant Maaike Vandermosten; KU Leuven,

Grant/Award Number: OT/12/044
\end{abstract}

\begin{abstract}
There is an ongoing debate whether phonological deficits in dyslexics should be attributed to (a) less specified representations of speech sounds, like suggested by studies in young children with a familial risk for dyslexia, or (b) to an impaired access to these phonemic representations, as suggested by studies in adults with dyslexia. These conflicting findings are rooted in between study differences in sample characteristics and/or testing techniques. The current study uses the same multivariate functional MRI (fMRI) approach as previously used in adults with dyslexia to investigate phonemic representations in 30 beginning readers with a familial risk and 24 beginning readers without a familial risk of dyslexia, of whom 20 were later retrospectively classified as dyslexic. Based on fMRI response patterns evoked by listening to different utterances of $/ \mathrm{bA} /$ and $/ \mathrm{dA} /$ sounds, multivoxel analyses indicate that the underlying activation patterns of the two phonemes were distinct in children with a low family risk but not in children with high family risk. However, no group differences were observed between children that were later classified as typical versus dyslexic readers, regardless of their family risk status, indicating that poor phonemic representations constitute a risk for dyslexia but are not sufficient to result in reading problems. We hypothesize that poor phonemic representations are trait (family risk) and not state (dyslexia) dependent, and that representational deficits only lead to reading difficulties when they are present in conjunction with other neuroanatomical or-functional deficits.
\end{abstract}

\section{KEYWORDS}

beginning readers, dyslexia, multivariate $\mathrm{MMRI}$, MVPA, phoneme representations, phonological deficit

\section{1 | INTRODUCTION}

Dyslexia is defined as a neurodevelopmental disorder that is characterized by persistent reading and/or spelling problems that cannot be explained by other factors such as IQ, motivation, sensory impairments and/or schooling (Peterson \& Pennington, 2015). It sets lifelong hindrances to achieving academic and professional success, and it often affects a person's psychosocial wellbeing (Boetsch, Green, \&
Pennington, 1996). To counter these negative long-term effects, it is of outmost importance to identify at an early stage children who will develop dyslexia later on. In fact, growing evidence shows that intervention studies at a pre-diagnostic age are more effective than later in life (Torgesen, 2000, 2002; Wanzek \& Vaughn, 2007). Yet early identification requires insight in the different factors that cause later reading and spelling deficits, and at the moment, the sensitivity and specificity of pre-diagnostic cognitive and neural measures is still 
insufficient to reliably predict and prevent dyslexia (for a review see Ozernov-Palchik \& Gaab, 2016).

This is not surprising when considering the multifactorial nature of dyslexia, that is, dyslexia is explained by a complex interplay of several cognitive and neural factors, with great inter-subject variability in the weighting of each of these factors (Pennington, 2006). Within this multifactorial framework, at an early age, phonological processing is often considered the most important factor relative to other reading-related skills such as visual attention, temporal auditory processing, oral language skills and short-term memory (MelbyLervåg \& Lervåg, 2012; Ramus, 2003; Saksida et al., 2016). More specifically, relative to the other skills, phonological processing - and in particular phonemic awareness (Melby-Lervåg, Lyster, \& Hulme, 2012) - shows the highest predictive power for later reading abilities (Ozernov-Palchik \& Gaab, 2016), the largest discrepancy between dyslexic and typical readers (Melby-Lervåg et al., 2012; Noordenbos \& Serniclaes, 2015), the largest training effects on reading (Bus \& Van ljzendoorn, 1999) and the highest proportion of poorly performing dyslexics (Saksida et al., 2016). Since phonological processing tasks require a diverse set of mental operations on the underlying speech sound representations (i.e. manipulations, retrieval and storage), it has been a longstanding belief that a common root for these phonological problems lies in a poor quality of these representations (Snowling, 2000; Vellutino, Fletcher, \& Snowling, 2004). However, when using phonological processing tasks, it is impossible to unravel whether phonological problems are rooted in the poor quality of the phonemic representations or in the metalinguistic processes operated upon them, also called the access problem (Ramus \& Szenkovits, 2008). In our study, we will precisely target phonemic representations in the brain and investigate them at a pre-diagnostic age.

From a developmental perspective, phonemic representations are, in contrast to Chomsky's earlier view (Chomsky \& Halle, 1968), not innate but gradually constructed through input of the language environment, resulting in mother-language specific phonemic representations (Kuhl, 2004). This construction process seems to be dependent on two main mechanisms (Kuhl, 2004). First, the auditory ability to detect small acoustic changes in the speech signal (such as formant transitions or envelope dynamics), which contribute to phoneme identification (Diehl, 2008; Moore, 2008). Second, the ability to extract the distributional information of these acoustic cues within a natural language in order to learn which acoustic differences are relevant to distinguish different phoneme categories and which ones should be considered linguistically irrelevant - also referred to as statistical learning (Maye, Werker, \& Gerken, 2002). In children and adults with dyslexia, poorer performance has been observed for both the auditory processing (Boets et al., 2011; Goswami, Power, Lallier, \& Facoetti, 2014; Hämäläinen, Salminen, \& Leppänen; Vandermosten et al., 2010, 2011) and the statistical learning mechanism (Bonte, Poelmans, \& Blomert, 2007; Gabay \& Holt, 2015; Vandermosten, Wouters, Ghesquière, \& Golestani, 2019), which indirectly supports the idea that the resulting product - that is the phonemic representations - are not well formed or are immature in readers with dyslexia.

\section{Research Highlights}

- The general assumption of a phonemic representational deficit in dyslexia has recently been questioned by an adult functional MRI (fMRI) study showing no representational deficit.

- Using a similar fMRI design and analyses, children with a familial risk for dyslexia (grade 2) do display less distinctive phonemic representations in bilateral temporal regions.

- This finding was confirmed using distributed and local searchlight multivariate fMRI analyses and robust statistical testing.

- The observed representational deficit was driven by familial (genetic) risk and not by the eventual reading status obtained.

This idea is further supported by deficits observed in children with dyslexia when tested via implicit phonological tasks that are designed to tap more directly on the underlying deficient representations, such as categorical perception (see meta-analysis of Noordenbos \& Serniclaes, 2015), lexical gating and priming experiments (Boada \& Pennington, 2006; Bonte \& Blomert, 2004; Matsala, 1997). However, a series of similar experiments in adult university students did not find support for a problem related to the nature of phonological representations but rather supported an access problem (Ramus \& Szenkovits, 2008; Dickie, Ota, \& Clark, 2013). It should be acknowledged that these cognitive experiments cannot purely measure either representation or access since the measured outcome is the result of the dynamic interplay between them and deficits can be biased by attentional problems, which are often present in the dyslexic population (Hendren, Haft, Black, White, \& Hoeft, 2018; Hong, 2014).

Electroencephalographic (EEG) experiments, which have the advantage of capturing pre-attentive processes without performance-related constraints, demonstrate less distinctive neural processing of speech sounds in children with dyslexia (Hornickel et al., 2009, 2011, 2013), and even in kindergartners (Noordenbos, Segers, Serniclaes, Mitterer, \& Verhoeven, 2012), infants and newborns (Molfese 2000; Guttorm, Leppänen, Richardson, \& Lyytinen, 2001; van Herten et al, 2008) with a family risk for dyslexia. These early differences in speech processing seem to be even larger between family risk groups than between reading groups, indicating a closer link of speech processing deficits with the trait than with the state of dyslexia (Hakvoort, Van Der Leij, Maurits, Maassen, \& Van Zuijen, 2015). This trait-dependence has recently been confirmed by a structural MRI study showing that decreased laterality of the planum temporale - a region assumed to host phonemic representations - was related to family risk rather than to reading level differences both in adolescents and pre-readers (Vanderauwera, Altarelli, Vandermosten, De Vos, et al., 2018). Nevertheless, given that in many of the reported EEG-studies the speech sounds presented 
TAB LE 1 Descriptive statistics on participant characteristics, literacy skills and cognitive skills in children with a family risk for dyslexia (FRD+) and without a family risk (FRD-). Test statistics on group comparison are also provided

\begin{tabular}{|c|c|c|c|}
\hline & $\begin{array}{l}\text { FRD- } \\
(n=24)\end{array}$ & $\begin{array}{l}\text { FRD }+ \\
(n=30)\end{array}$ & Test statistics \\
\hline \multicolumn{4}{|c|}{ Participant characteristics } \\
\hline Sex (male/female) & $16 / 8$ & $18 / 12$ & $\begin{array}{c}x^{2}(1)=0.254, \\
p=0.614\end{array}$ \\
\hline SES & $5.25(1.62)$ & $5.77(1.33)$ & $\begin{array}{c}t(52)=-1.29 \\
p=0.204\end{array}$ \\
\hline $\begin{array}{l}\text { WISC block } \\
\text { patterns }\end{array}$ & $28.3(10.0)$ & $25.5(10.1)$ & $\begin{array}{c}t(52)=0.99 \\
p=0.329\end{array}$ \\
\hline WISC vocabulary & $16.8(4.4)$ & $18.5(4.1)$ & $\begin{array}{c}t(52)=-1.46 \\
p=0.151\end{array}$ \\
\hline $\begin{array}{l}\text { Handedness (Left/ } \\
\text { Right/Ambidexter) }\end{array}$ & $1 / 23 / 0$ & $6 / 23 / 1$ & $\begin{array}{c}X^{2}(2)=3.95 \\
p=0.1167\end{array}$ \\
\hline $\begin{array}{l}\text { Age fMRI (in } \\
\text { months) }\end{array}$ & $95.5(3.0)$ & $95.2(3.3)$ & $\begin{array}{c}\mathrm{t}(52)=0.31 \\
p=0.759\end{array}$ \\
\hline $\begin{array}{l}\text { In-scanner motion } \\
\text { (RMS) }\end{array}$ & $0.52(0.41)$ & $0.52(0.50)$ & $\begin{array}{c}t(52)=-0.48 \\
p=0.633\end{array}$ \\
\hline $\begin{array}{l}\text { In-scanner detec- } \\
\text { tion rate catch } \\
\text { trials }\end{array}$ & $0.93(0.12)$ & $0.86(0.25)$ & $\begin{array}{c}t(52)=1.28 \\
p=0.205\end{array}$ \\
\hline \multicolumn{4}{|c|}{ Literacy skills (start grade 3 ) } \\
\hline Word reading & $43.6(13.6)$ & $30.6(15.9)$ & $\begin{array}{c}t(52)=3.18 \\
p=0.003\end{array}$ \\
\hline $\begin{array}{l}\text { Pseudo-word } \\
\text { reading }\end{array}$ & $31.5(12.2)$ & $21.6(11.9)$ & $\begin{array}{c}t(52)=2.99 \\
p=0.004\end{array}$ \\
\hline Spelling & $46.9(6.6)$ & $37.4(10.8)$ & $\begin{array}{c}t(52)=3.76 \\
p<0.001\end{array}$ \\
\hline \multicolumn{4}{|c|}{ Cognitive skills (start grade 3 ) } \\
\hline $\begin{array}{l}\text { PA: Phoneme } \\
\text { deletion }\end{array}$ & $19.2(4.7)$ & $16.0(6.7)$ & $\begin{array}{c}t(52)=2.00 \\
p=0.050\end{array}$ \\
\hline PA: Spoonerisms & $32.2(9.9)$ & $27.3(12.3)$ & $\begin{array}{c}t(52)=1.61 \\
p=0.113\end{array}$ \\
\hline RAN objects & $1.00(0.19)$ & $0.91(0.21)$ & $\begin{array}{c}t(52)=1.62 \\
p=0.112\end{array}$ \\
\hline RAN: colours & $\begin{array}{l}1.06 \\
(0.22)\end{array}$ & $0.97(0.21)$ & $\begin{array}{c}t(52)=1.52 \\
p=0.134\end{array}$ \\
\hline RAN: letters & $\begin{array}{l}1.63 \\
(0.35)\end{array}$ & $1.38(0.28)$ & $\begin{array}{c}t(52)=2.93 \\
p=0.005\end{array}$ \\
\hline RAN: digits & $1.73(0.21)$ & $1.49(0.36)$ & $\begin{array}{c}t(52)=2.65 \\
p=0.011\end{array}$ \\
\hline vSTM: digitspan & $\begin{array}{c}10.08 \\
(2.06)\end{array}$ & $9.83(1.98)$ & $\begin{array}{r}t(52)=45 \\
p=0.653\end{array}$ \\
\hline $\begin{array}{l}\text { vSTM: nonword } \\
\text { repetition }\end{array}$ & $26.5(5.3)$ & $27.7(5.5)$ & $\begin{array}{c}t(52)=-0.81 \\
p=0.421\end{array}$ \\
\hline $\begin{array}{l}\text { Orthographic } \\
\text { knowledge }\end{array}$ & $44.4(7.4)$ & $37.0(11.2)$ & $\begin{array}{c}t(52)=2.81 \\
p=0.007\end{array}$ \\
\hline
\end{tabular}

Abbreviations: $\mathrm{fMRI}$, functional MRI; RMS, root mean square.

only differed between and not within phonemic categories (i.e. no acoustic variability within a category) (e.g. Guttorm, Leppänen, Tolvanen, \& Lyytinen, 2003), the observed deficits could also reflect a generally decreased auditory sensitivity to distinguishing cues embedded in these speech sounds (Hämäläinen, Salminen, \& Leppänen, 2012; Ziegler, Pech-Georgel, George, \& Lorenzi, 2009). Additionally, in the few EEG studies that did present acoustic variants within phoneme categories (e.g. Noordenbos et al., 2012), the analyses did not allow to compare neural responses of between- versus within-phoneme differences in individual subjects, hence they cannot capture the actual quality of phonemic representations at the individual level.

In a similar vein, traditional univariate functional magnetic resonance (fMRI) studies have shown reduced responsiveness to speech in dyslexic's posterior superior temporal cortex (Blau, van Atteveldt, Ekkebus, Goebel, \& Blomert, 2009; Blau et al., 2010; Monzalvo, Fluss, Billard, Dehaene, \& Dehaene-Lambertz, 2012). These studies however, examined activation in only one location (voxel) at a time, thereby failing to capture more subtle activation differences between phonemes. Multivoxel pattern analysis (MVPA) enabled the investigation of phonemic brain representations in a more direct way. MVPA extracts patterns of fMRI activations across multiple brain locations (voxels) simultaneously, which has been shown to enable decoding of phoneme categories independently of acoustic variability (e.g. intra- and interspeaker variability, co-articulation,...) (Formisano, De Martino, Bonte, \& Goebel, 2008; Lee, Turkeltaub, Granger, \& Raizada, 2012; Raizada et al., 2010). In a recent study, Boets et al. (2013) applied this technique in university students with dyslexia. However, despite the ability of the technique to decode phoneme categories from the activity patterns, no significant difference was observed between typical and dyslexic readers in the degree of this phonemic decoding. Since this null-finding was complemented by a decreased functional and structural connectivity from the auditory regions hosting these representations toward inferior frontal regions in dyslexic readers, the results were interpreted as evidence for an access rather than a representational problem.

In the current study we aim to unravel this striking pattern of opposite findings, namely longitudinal EEG-studies providing indirect support for a phonemic representational deficit in young children with a family risk for dyslexia, and multivariate fMRI findings indicating an access rather than a representational deficit in adults with dyslexia. The most straightforward hypothesis is that representational deficits are only observable in children and are diminished in (compensated) adults (Boets, 2014). Given that developmental and/ or compensational mechanisms might explain the lack of phonemic representational deficits in adults with dyslexia, we aim testing phonemic brain representations in young beginning readers (grade 2) with (a risk for) dyslexia using MVPA methods sensitive to quantifying these representations (Boets et al., 2013; Bonte, Hausfeld, Scharke, Valente, \& Formisano, 2014; Formisano et al., 2008; Lee et al., 2012). In addition, since it has been suggested that auditory and/ or speech perception deficits might be more related to the family risk of dyslexia (i.e. trait) and less to the reading difficulties themselves (i.e. state) (Hakvoort et al., 2015; Vanderauwera, Altarelli, Vandermosten, Wouters, \& Ghesquière, 2018), we will compare differences in phonemic representations between children with 
and without a family risk for dyslexia (i.e. FRD+ vs. FRD-) as well as between children who were later classified with dyslexia (based on persistent reading problems in grade 3, 4 and 5) and age-matched typical readers (i.e. DR vs. TR). Hence, we will investigate whether atypical neural patterns of phonemic representations can be observed early in reading development, and if they can, whether they are state-related (i.e. related to the observed reading problems) or trait-related (i.e. related to the family risk).

\section{2 | METHOD}

\section{1 | Participants}

This study is part of a larger longitudinal project of the Dyslexia Collaboration KU Leuven in which behavioural measures on reading, spelling, phonological, orthographic, speech and auditory processing are acquired yearly, and MRI and EEG measures are collected every 2 years. At the start, 87 pre-reading children were recruited, consisting of 44 children with a familial risk for dyslexia (defined as having a first degree relative with a dyslexia diagnosis) and 43 individually matched children without a familial risk (for details see Vanvooren, Poelmans, Hofmann, Ghesquière, \& Wouters, 2014). The number of recruited participants was determined by the willingness to participate of family risk children (for which the best matching control child in the class was selected) and the feasibility of collecting a large set of data longitudinally. For the current study, MRI-data were acquired at the end of Grade 2 in 66 children, of whom 62 participated in the fMRI experiment. Data of three subjects could not be included due to incomplete fMRI sessions. In addition, data of three subjects were excluded due to excessive head motion during fMRI acquisition (i.e. motion relative to the previous volume averaged across the four runs $>2 \mathrm{~mm}$ ) and data of two subjects were excluded due to excessive head motion during structural MRI (T1) acquisition (i.e. severe ghosting effects and low SNR resulting in failed normalization). The final dataset on which analyses were conducted consisted of 54 subjects. Behavioural data were collected each year at the beginning of the school year (from kindergarten until grade 5). More details on the behavioural tests can be found in previous publications on this longitudinal project (Vanderauwera, De Vos, et al., 2018; Vandermosten et al., 2015). Tables 1 and 2 provide literacy and cognitive data at

\begin{tabular}{|c|c|c|c|}
\hline & $\begin{array}{l}\text { TR } \\
(n=34)\end{array}$ & $\begin{array}{l}\text { DR } \\
(n=20)\end{array}$ & Test statistics \\
\hline \multicolumn{4}{|l|}{ Participant characteristics } \\
\hline Sex (male/female) & $21 / 13$ & $13 / 7$ & $X^{2}(1)=0.06, p=0.812$ \\
\hline SES & $5.62(1.42)$ & $5.40(1.60)$ & $t(52)=0.52, p=0.606$ \\
\hline WISC block patterns & $26.2(8.9)$ & $27.7(11.8)$ & $\begin{array}{c}t(52)=-0.53 \\
p=0.596\end{array}$ \\
\hline WISC vocabulary & $17.9(4.8)$ & $17.5(3.3)$ & $t(52)=0.36, p=0.719$ \\
\hline $\begin{array}{l}\text { Handedness (Left/Right/ } \\
\text { Ambidexter) }\end{array}$ & $5 / 28 / 1$ & $2 / 18 / 0$ & $X^{2}(2)=0.89, p=0.810$ \\
\hline Age fMRI (in months) & $95.7(3.1)$ & $94.8(3.2)$ & $t(52)=1.09, p=0.282$ \\
\hline In-scanner motion (RMS) & $0.48(0.42)$ & $0.68(0.50)$ & $\begin{array}{c}t(52)=-1.59 \\
p=0.117\end{array}$ \\
\hline $\begin{array}{l}\text { In-scanner detection rate } \\
\text { catch trials }\end{array}$ & $0.88(0.25)$ & $0.90(0.10)$ & $\begin{array}{c}t(52)=-0.35 \\
p=0.731\end{array}$ \\
\hline \multicolumn{4}{|l|}{ Literacy skills (start grade 3 ) } \\
\hline Word reading & $45.9(11.4)$ & $20.1(7.8)$ & $t(52)=9.01, p<0.001$ \\
\hline Pseudo-word reading & $32.9(10.5)$ & $14.3(6.8)$ & $t(52)=7.09, p<0.001$ \\
\hline Spelling & $46.2(8.0)$ & $33.9(9.2)$ & $t(52)=4.85, p<0.001$ \\
\hline \multicolumn{4}{|l|}{ Cognitive skills (start grade 3 ) } \\
\hline PA: Phoneme deletion & $19.8(1.9)$ & $13.4(5.8)$ & $t(52)=4.34, p<0.001$ \\
\hline PA: Spoonerisms & $34.2(9.3)$ & $21.4(10.2)$ & $t(52)=4.69, p<0.001$ \\
\hline RAN objects & $1.00(0.18)$ & $0.86(0.22)$ & $t(52)=2.56, p=0.014$ \\
\hline RAN: colours & $1.07(0.21)$ & $0.91(0.20)$ & $t(52)=2.73, p=0.009$ \\
\hline RAN: letters & $1.61(0.34)$ & $1.29(0.20)$ & $t(52)=3.79, p<0.001$ \\
\hline RAN: digits & $1.75(0.28)$ & $1.33(0.28)$ & $t(52)=5.35, p<0.001$ \\
\hline vSTM: digitspan & $10.1(1.9)$ & $9.8(2.2)$ & $t(52)=0.54, p=0.589$ \\
\hline vSTM: nonword repetition & $27.9(5.1)$ & $25.9(5.8)$ & $t(52)=1.29, p=0.204$ \\
\hline Orthographic knowledge & $45.4(7.8)$ & $31.5(7.9)$ & $t(52)=6.32, p<0.001$ \\
\hline
\end{tabular}

TABLE 2 Descriptive statistics on participant characteristics, literacy skills and cognitive skills in children with typical reading skills (TR) and with dyslexia (DR). Test statistics on group comparison are also provided

Abbreviations: fMRI, functional MRI; RMS, root mean square. 
the time point the closest to the fMRI data acquisition, namely the beginning of grade 3 . The average gap between the collection of the $\mathrm{FMRI}$ data (end of grade 2) and these behavioural data are 92 days (SD 29 days). The selected group of 54 children consisted of 30 children with a familial risk for dyslexia (FRD+) and 24 children without a familial risk (FRD-). In addition, the group consisted of 20 children with dyslexia (DR; 5 without and 15 with familial risk) and 34 typical readers (TR; 19 without and 15 with familial risk). The classification of dyslexia was based on literacy achievement at third, fourth and fifth grade, assessed with standardized word reading and pseudoword reading (van den Bos, Spelberg, Scheepstra, \& de Vries, 1994; Brus \& Voeten, 1973; Dudal, 1997). We categorized children as dyslexic when they had scored below percentile 10 on the same standardized reading test (either word or pseudoword reading test) at all three time points. Note that all but one of our DR participants were categorized based on word reading being below pc 10 at three time points, whereas one DR participant was categorized based on pseudoword reading being below pc 10 at three time points (but he also had word reading scores below pc 10 at two time points). This strict classification of dyslexic readers incorporates the severity and persistence criteria defined in DSM-V (American Psychiatric Association, 2013). Tables 1 and 2 provide participant characteristics such as IQ, sex, SES and age, as well as, reading and cognitive skills, with Table 1 comparing FRD- versus FRD+ and Table 2 comparing TR versus DR. In the Data S1 we provide the characteristics of each of the four subgroups (i.e. TR_FRD-, TR_FRD+, DR_FRD-, DR_FRD+), but the sample size of DR_FRD- was too low $(N=5)$ to provide test statistics for these separate subgroup comparisons.

\subsection{Speech stimuli}

Our fMRI experiment focuses on the phonemic representations of two stop consonants, /b/ and /d/ (presented in combination with the vowel /A/), differing in the spectrotemporal characteristics of their second formant. Dyslexic readers tend to have difficulties in processing these spectrotemporal cues, often also reflected in poorer categorical perception of stop consonants (Noordenbos \& Serniclaes, 2015; Vandermosten et al., 2011). We integrated the two target sounds within consonant-vowel-consonant-vowel (CVCV) syllables, that is /bAbA/ and /dAdA/, each spoken four times by four different male speakers. Multiple speakers were used to introduce acoustic variation to the stimuli. Average length, F1 and F2 (and range) of the two CVCV conditions were: /bAbA/: $M_{\text {length }}=1,040 \mathrm{~ms}$ (range 970-1,110 ms), $M_{F 1}=676 \mathrm{~Hz}$ (range 672-684 Hz), $M_{F 2}=1,264 \mathrm{~Hz}$ (range 1,130-1,379 Hz), $M_{F 2 \text { onset }}=1,085 \mathrm{~Hz}$ (range 925-1,245 Hz); $/ \mathrm{dAdA} /$ : Mlength $=1,080 \mathrm{~ms}$ (range 990-1,180 ms), $\mathrm{M}_{\mathrm{F} 1}=702 \mathrm{~Hz}$ (range 620-775 Hz), $M_{F 2}=1,335 \mathrm{~Hz}$ (range 1,200-1,480 Hz), $M_{\text {F2onset }}=1,635 \mathrm{~Hz}$ (range 1,500-1,755 Hz). Inspection of these values within speakers and within CVCV conditions show that the between-phoneme acoustic variance within a speaker is in the same range as the between-speaker acoustic variance within a CVCV condition, hence acoustically, the phonemic contrasts are as similar/different as the allophonic (speaker-induced) contrasts. Sound intensity level was numerically equated across stimuli by matching root mean square (RMS) values. The /bAbA/ and /dAdA/ stimuli were identical to the ones used in Boets et al. (2013). Stimuli were presented binaurally at a comfortable hearing level using Presentation software (Neurobehavioral Systems Inc.) and a customized air-conduction sound delivery system (MR Confon Audio Amplifier mkII). The headphones attenuated the surrounding scanning noise with about 30-40 dB SPL along the 0.1-10.0 kHz domain.

\section{3 | MRI image acquisition}

During a preparation session (around $30 \mathrm{~min}$ ) (Vanderauwera, Wouters, Vandermosten, \& Ghesquière, 2017), all children were acquainted to the scanner environment and were trained to reduce head movements (for a similar approach see Theys, Wouters, \& Ghesquière, 2014). The MRI session consisted of 4 functional MRI (fMRI) scans, an anatomical scan (T1-weighted) and a diffusion weighted imaging scan, using a $3 \mathrm{~T}$ Philips scanner (Best, The Netherlands) with a 32-channel head coil. The total time spent in the scanner was approximately $45 \mathrm{~min}$. Diffusion MRI data (11 min) were acquired in the beginning of the sequence, but are not used in this study. In the fMRI session, blood-oxygen-level-dependent signals were measured using a T2*-sensitive gradient echo planar imaging sequence, including 36 slices with thickness of $3 \mathrm{~mm}$ and in-plane resolution of 2.4. To minimize scanning time in the young children, the field of view was set at $230 \times 108 \times 230 \mathrm{~mm}$ (ap, fh, rl), which covered most of the brain except for the inferior temporal and frontal regions and the cerebellum in some subjects. In all subjects, fMRI acquisition covered the superior and middle temporal regions, on which $\mathrm{fMRI}$ analyses were conducted (see paragraph 5 for more details on the temporal mask). Volume acquisition was $1.85 \mathrm{~s}$ followed by a silent delay of $1.65 \mathrm{~s}$ in which stimuli were presented, resulting in a total repetition time of $3.5 \mathrm{~s}$. This sparse sampling approach was used to minimize the effects of scanning noise on speech perception. Each fMRI run lasted around 4 min (more details in paragraph fMRI paradigm), resulting in approximately 16 min of fMRI acquisition. The anatomical T1-weighted sequence was acquired in between the first two and last two fMRI runs, and lasted around $7 \mathrm{~min}$ (FOV of $250 \times 250 \mathrm{~mm}, 182$ coronal slices and $1.2 \mathrm{~mm}$ slice thickness).

\section{4 | fMRI paradigm}

The fMRI experiment consisted of four runs, using a blocked sparsesampling paradigm, in which subjects listened to /bAbA/ items, / $\mathrm{dAdA}$ / items, silence and catch trials (see Figure 1). Each run consisted of four blocks of /bAbA/ items, four blocks of /dAdA/ items, four blocks of silence and three catch trials. Each of the /bAbA/, /dAdA/ and silence blocks was composed of four trials. For the /bAbA/ and / $\mathrm{dAdA} /$ blocks, each of the four trials was pronounced by a different speaker, hence within a block the syllables were phonetically identical but varied acoustically. Different from the MVPA-study in dyslexic adults (Boets et al., 2013), we used a passive listening paradigm which enabled minimizing attentional and meta-linguistic top-down 

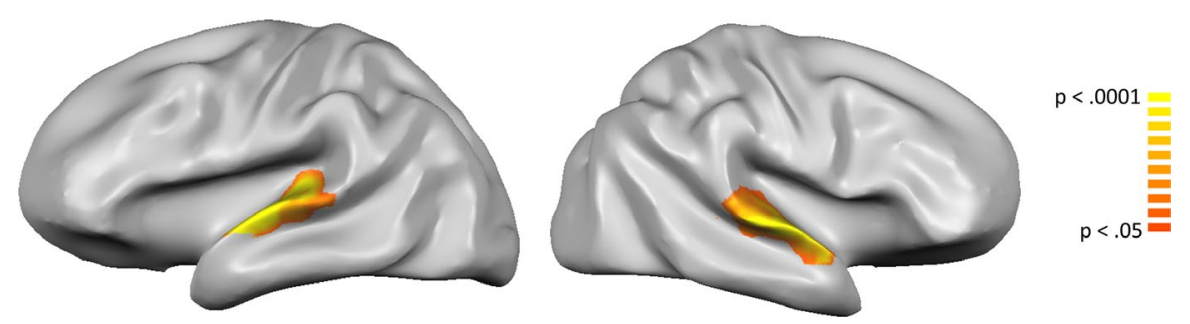

FIGURE 1 Whole brain activation map for listening to speech sounds versus silence across all subjects. The activation maps are projected on the inflated surface of the left and right hemispheres of one representative child. Maps are cluster size corrected (threshold $=20$ voxels) at $p<0.05$

effects that can otherwise be intermingled due to the sluggish dynamics of the BOLD signal. Yet in order to ensure attentive listening to the speech sounds, per run three catch trials were included. A catch trial consisted of the presentation of a /zAzA/ syllable, pronounced by one of two other male speakers, and was followed by a silence trial. Children were instructed to press a response button when a /zAzA/ syllable was heard, which was a relatively easy task, confirmed by an average correct detection rate of $88 \%$ (see Table 1 for behavioural responses). The order of blocks within run 1 and 3 was identical and counterbalanced to the order in run 2 and 4.

\section{5 | fMRI data analyses}

Imaging data were analysed using Brain Voyager QX version 2.8. (Brain Innovation) (Goebel, 2012) and custom-made MATLAB (The MathWorks) routines. Functional data were corrected for 3D motion-artefacts (trilinear sinc interpolation), slice scan time differences (using sinc interpolation), linear drifts and low-frequency non-linear drifts (high pass filter $\leq 2$ cycles per time course) (Goebel, Esposito, \& Formisano, 2006). No spatial or temporal smoothing was applied. According to the standard analysis scheme in Brain Voyager QX (Goebel et al., 2006), anatomical data of each participant were corrected for intensity inhomogeneity, functional images were coregistered to these individual anatomical images, and both anatomical and functional data were normalized to Talairach space (Talairach \& Tournoux, 1988).

\subsection{1 | Motion}

Given the young age of the children, it was important to carefully control for motion effects. We therefore performed four steps. First, we determined for each subject its relative RMS displacement (based on 3 translation and 3 rotation parameters) averaged across the four runs. When RMS displacement exceeded $2 \mathrm{~mm}$, we excluded the data of these subjects from the analyses. This was the case for three subjects, as indicated in the participant-section. Note that data of two additional subjects needed to be excluded due to excessive motion during the T1-scan (see Participants). Second, for all remaining subjects we determined which volumes showed spikes in the motion data, defined as volumes with RMS displacement of more than a voxel size ( $3 \mathrm{~mm}$ ). These volumes were not taken into account for the analyses. Third, for the remaining volumes motion parameters were regressed out. Finally, we compared the average RMS across the four runs between our groups (FRD+ vs. FRD- and TR vs. DR). The differences were not significant between FRD- and FRD+ $(t(52)=-0.48, p=0.633)$ nor between $\operatorname{TR}$ and $\mathrm{DR}(t(52)=-1.59$, $p=0.117)$.

\subsection{2 | Temporal mask}

Given the focused activation maps when listening to the speech sounds (see Figure 1 for whole brain univariate analyses) and given
Superior Temporal (ST) mask
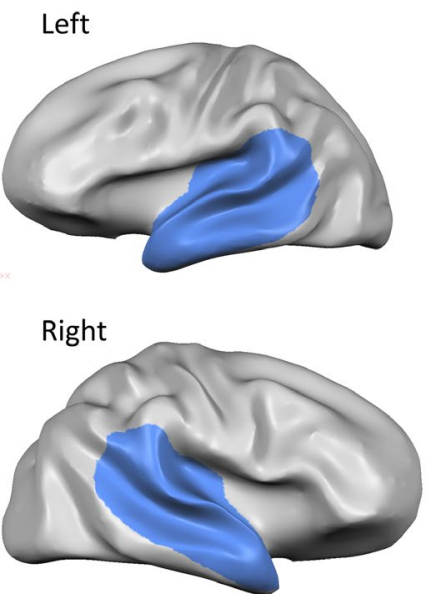

Selected voxels within ST mask
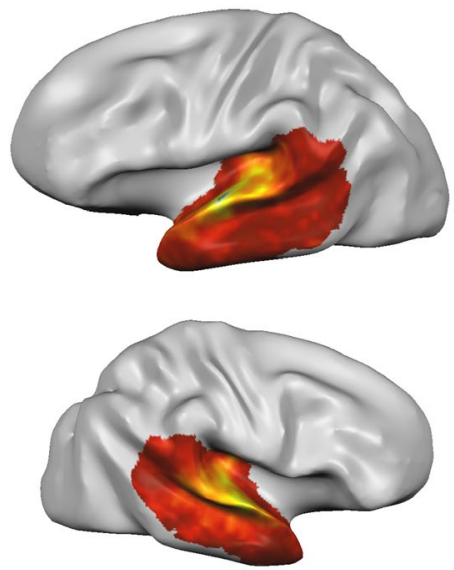

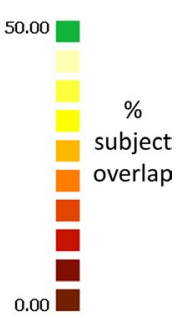

FIGURE 2 (a) Left and right Superior Temporal (ST) masks. The temporal masks are projected on the inflated surface of the left and right hemispheres of one representative child. (b) Probabilistic maps illustrating amount of subject overlap for the individually determined 500 most active voxels across the left and right temporal masks. The lighter the colour, the higher the across-subject consistency 
that our FOV in functional scans did not cover the full brain in all children (see section Data Acquisition), fMRI analyses were restricted to superior temporal regions (ST mask). To this end, we created a left and right ST mask (see left panel of Figure 2) which was previously observed to encompass univariate responses to short meaningless speech sounds (Bonte et al., 2014), as well as to contain vowel (Bonte et al., 2014; Formisano et al., 2008) and syllable (Bonte, Correia, Keetels, Vroomen, \& Formisano, 2017; Kilian-Hutten, Valente, Vroomen, \& Formisano, 2011) representations.

\subsection{3 | Univariate fMRI analyses}

Population-level inferences concerning BOLD signal changes between the experimental conditions and between groups were based on a random effects model with predictors separated for each subject. Statistical comparison between conditions and groups were based on percentage normalized beta-values within the superior temporal masks. We used a factorial model including one within subject factor (i.e. phonemic condition: /bAbA/ vs. /dAdA/) and one between subject factor (i.e. either reading group or family group). In this case, all the time courses of associated voxels within the ST mask are first averaged before the analysis takes place (basically treating the whole region as one functional unit), hence there is no need for a multiple comparisons correction.

\subsection{4 | MVPA analyses}

Multivoxel pattern analysis was employed to investigate differences in superior temporal response patterns evoked by the / $\mathrm{bAbA} /$ versus /dAdA/ sounds. Phonemic discrimination was assessed using a relative pattern similarity approach between responses to /bAbA/ and /dAdA/ syllables across two independent sets of runs (Haxby et al., 2001). Pattern similarities were computed using cross-correlation (Pearson correlation), and performed for the two syllable types (/bAbA/ and /dAdA/) across both sets of runs (set 1: run 1 and 4, set 2: run 2 and 3), resulting in a 2 by 2 correlation matrix (Fisher transformed). A coefficient of phonemic discrimination was then derived from the difference of (a) similarities between the same syllables across run sets and (b) the similarities between different syllables across run sets. One decoding coefficient was calculated per subject and used in second level group statistics (random effects) by applying resampling methods (Nichols \& Holmes, 2001). Averaged decoding coefficients were computed per group using bootstrapping ( $n=10,000$, with replacement). To test for significant decoding within groups, statistics were computed using sign-flipping permutations ( $n=10,000$ ). At each permutation, a random selection of coefficients was multiplied by -1 , and group averaged. Probability of $\mathrm{HO}$ was computed by dividing the area of the permuted distribution equal to or larger than the group averaged coefficient calculated above +1 , divided by the number of permutations +1 . To test for significant differences in phonemic decoding between groups (TR vs. DR, and FRD- vs. FRD+), statistics were computed by randomly exchanging coefficients across groups ( $n=10,000$ permutations) and computing the coefficient difference between the two groups. Similarly to within-group statistics, the probability of $\mathrm{HO}$ was computed against the permuted distribution.

In MVPA, feature selection (i.e. voxel selection) is important to improve model generalization by reducing overfitting related to the large dimensionality of $\mathrm{fMRI}$ data, and to improve the localization and interpretation of results. Feature (voxel) selection comprised two distinct approaches. First, and following our expectations, we tested whether phonemic representation was present in a distributed pattern of voxel activations within auditory cortical regions (Bonte et al., 2014; Formisano et al., 2008). Accordingly, we applied our bilateral ST mask, as indicated above. Within each hemispheric mask, a second level feature selection comprised univariate activation, by selecting the most active 500 voxels within the ST mask irrespective of the syllable condition, while respecting the training/testing cross-validation scheme described below (selection was performed using the training set only at each cross-validation fold). This procedure was employed for a bilateral (left-hemisphere ST mask and right-hemisphere ST mask) selection, as well as for each hemisphere separately. Second, we tested whether phonemic discrimination is focally represented in patterns comprising neighbouring voxels by means of a searchlight approach across the ST masks (Kriegeskorte, Goebel, \& Bandettini, ). By combining a moving spherical searchlight (radius $=2.5$ voxels, i.e., $7.5 \mathrm{~mm}$ ) feature selection with the MVPA discrimination procedure described above, we investigated focal phonemic representation. The searchlight approach encompassed performing multiple tests along neighbouring voxel selections. Phonemic coefficients are depicted in the location of each searchlight centroid. To statistically correct for the multiple tests derived by searching within a cortical region, we computed a cluster size threshold correction by estimating maximum cluster size distributions using permutation testing as described above (i.e. for group differences: by randomly exchanging subjects between controls and DR; for individual group statistics, by randomly exchanging the sign of the decoding coefficients, or multiplication with -1). At each permutation, a t test was performed (two-sided for group differences and one-sided for group significance), followed by a $p$-value threshold (alpha $=0.05$ ). The size of the largest cluster at each permutation was stored (connectivity between voxels was 26, meaning that faces, edges or corners touched to form clusters). We then assessed corrected decoding significance of our original clusters $(p<0.05)$ with respect to the distribution of maximum clusters obtained from permutation testing. We report thresholded clusters at a quantile of 0.95

\section{3 | RESULTS}

We first examined trait-related (i.e. family risk related) differences by comparing FRD+ and FRD- groups, and second, we examined staterelated (i.e. reading outcome related) differences by comparing DR 
and TR groups. When significant group differences were observed, an additional step was performed investigating trait-related group differences while controlling for reading outcome (namely TR_FRD+ vs. TR_FRD-), and state-related group differences while controlling for family risk (namely TR_FRD+ vs. DR_FRD+.) We could not perform a likewise comparison with the DR_FRD- group given its low sample size $(N=5)$. Therefore, in Data $\mathrm{S} 1$, we provide descriptive information of the four subgroups (TR_FRD-, TR_FRD+, DR_FRD-, DR_FRD+) (see Figure S1 and Table S1) for illustrative purposes without testing these group differences for significance.

\section{1 | Univariate analyses}

Speech sounds evoked similar overall activation within the ST mask in FRD- and FRD+ children, indicating the absence of traitrelated differences. More specifically, no group differences were observed in the left ST mask when listening to /bAbA/ and / dAdA/ syllables $(F(1)=0.113, p=0.738)$ nor within the right ST mask $(F(1)=0.835, p=0.365)$. Regarding state-related differences, overall activation within the ST mask also did not show significant group differences between DR and TR children (left ST mask: $F(1)=1.277, p=0.264$; right ST mask: $F(1)=0.230, p=0.643$ ). Finally, no significant differences were observed between /bAbA/ and /dAdA/ conditions within the ST mask ( $p>0.905)$, confirming that univariate analyses were not sensitive enough to detect subtle phonemic differences.

\section{2 | Multivariate pattern analysis}

The more sensitive MVPA analysis comprised the two approaches described above. One in which MVPA analysis was restricted to a subject-specific ST mask (which consisted of the 500 most active voxels across the left and/or right ST mask), and a second one based on the searchlight procedure within the same masks.

In the first approach, we selected per subject the 500 most active voxels across the bilateral ST mask. Using this subject-specific temporal mask implies that in each subject and cross-validation fold the same amount of voxels is used for the MVPA-analyses, but the location of the voxels within the temporal mask may differ, as can be seen from the probability maps in the right panel of Figure 2. The probability maps in Figure 2 show the across subject consistency of the 500 voxels selected per subject in the bilateral ST masks. As indicated by the probabilistic maps of the selected voxels across subjects, the largest overlap between subjects lies in the bilateral auditory cortices with more variability in the surrounding regions. Importantly, overlap of voxel selections is not directly related with localization of phonemic information, which is purely attributed to the pattern as a whole.

MVPA-analysis was performed to examine within each group whether activation patterns for speech sounds belonging to the same phoneme are more similar than for speech sounds belonging to different phonemes (i.e. phonemic decoding), and to compare between groups whether the degree of phonemic decoding was different.
Trait-dependent (familial risk) neural decoding of phonemes

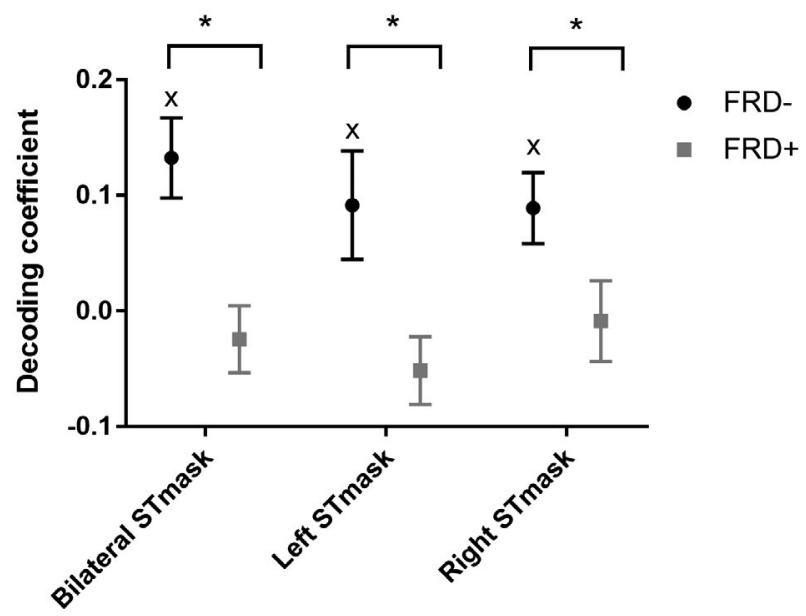

FIGURE 3 Group averaged (Mean [SE]) decoding coefficients for speech syllables. The coefficients represent the degree to which neural patterns of sounds belonging to the same phoneme are more similar than neural patterns belonging to different phonemes. Decoding was based on the individually determined 500 most active voxels within (a) the bilateral ST-mask, (b) the left ST-mask and (c) the right ST mask. ' $x$ ' indicates significant phonemic decoding at the group-level (i.e. significantly above zero); (*) indicates significant group differences in phonemic decoding

With regard to the trait-related differences, results indicated a significantly better phonemic decoding in the FRD- group than in the FRD+ group (see Figure 3). More specifically, MVPA-analysis across the bilateral ST-mask yielded a significantly different decoding coefficient between groups ( $p<0.001$ ), indicating that neural representations of phonemes are less distinctively specified in FRD+ relative to FRD- children. Indeed, within the FRD- group the mean decoding coefficient had a $p$-value $<0.001$ to fall within the permuted distribution. This means that for the FRD- group, the activation patterns for speech sounds belonging to the same phoneme are more similar than for speech sounds belonging to different phonemes, hence FRD- display distinct neural representations for phonemes. In the FRD+ group, however, the mean of the decoding coefficient fell within the permuted distribution with a $p$-value $=0.789$, hence indicating no significantly distinct neural decoding of the presented phonemes. When selecting the 500 most active voxels for MVPAanalyses separately from the left and right ST mask, these group differences were confirmed, with a significant group difference in neural phonemic decoding in the left ST-mask $(p=0.006)$ as well as in the right ST-mask $(p=0.025)$. Again, significant neural decoding of phonemes was only observed in the FRD- group (left: $p=0.035$; right: $p=0.005$ ), with no significant decoding in the FRD + group (left: $p=0.950$; right: $p=0.596$ ). Finally, the results were independent of the number of selected voxels, since selecting the double (1,000 voxels) or half (250 voxels) of the number of voxels resulted in the exact same pattern of results (for details see Table S2 in the Data S1).

Since both the FRD- and FRD+ group contained a combination of DR and TR, we further investigated trait-related group 

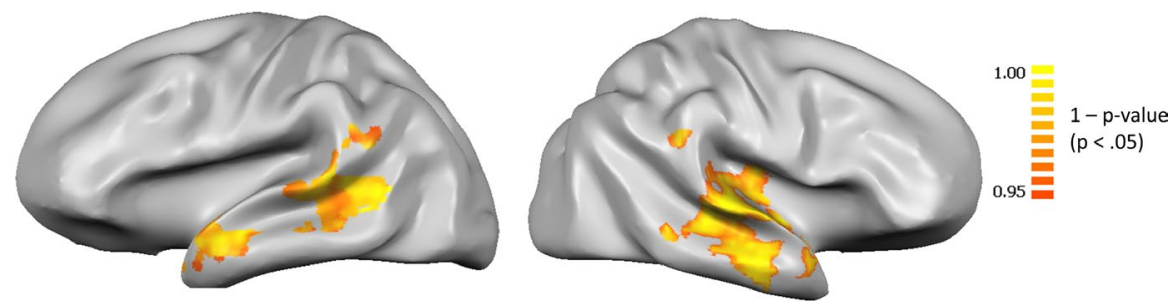

FIGURE 4 Statistical maps indicating the cortical areas that produced significant group differences in decoding accuracies between the low (FRD-) versus high (FRD+) family risk groups. Maps are based on a searchlight approach across the bilateral ST mask, statistically assessed using 2-sample $t$ tests and cluster-size corrected for multiple comparisons

differences by conducting a subgroup analysis controlled for reading outcome differences. That is, typical readers with low family risk (TR_FRD-) were compared to typical readers with a high family risk (TR_FRD+). MVPA analysis confirmed that there was better neural phonemic decoding across the bilateral ST mask in TR_FRD- relative to TR_FRD+ $(p=009)$, with significant decoding in TR_FRD- $(p=0.019)$ but not in TR_FRD+ $(p=0.907)$. This group difference was confirmed when neural decoding was investigated separately in the left $(p=0.028)$ and right ST $(p=0.009)$ mask, with better decoding in TR_FRD- (left: $p=0.093$; right: $p=0.019$ ) than in TR_FRD+ (left: $p=0.938$; right: $p=0.904$ ).

With regard to state-related differences, we observed no significant group differences in neural decoding of phonemes between TR and DR. More specifically, MVPA analysis across the left and right ST-mask displayed no significant difference in phoneme decoding between TR and DR ( $p=0.502)$. For the TR-group, consisting of both FRD+ and FRD- children, neural decoding of phonemes did not reach significance anymore $(p=0.085)$. As expected given the high number of FRD+ children within the DR group and the abovedescribed family-related results, also no significant decoding was observed within the DR-group ( $p=0.144$ ). The lack of group differences between TR and DR was also apparent when the voxels were selected from the left ST mask only $(p=0.46)$ or from the right ST mask only $(p=0.73)$. Furthermore, the pattern remained the same when we selected double or half of the number of voxels for MVPA analysis (see SI). Since both the DR and TR group contained a combination of FRD+ and FRD- children, we reran the analysis while controlling for family risk, namely by comparing typical readers with a high family risk and dyslexic readers with a high family risk, resulting again in the absence of a significant group difference $(p=0.879)$. This result was confirmed when neural decoding was examined separately in the left $(p=0.700)$ and right mask $(p=0.914)$.

In the searchlight approach, we investigated trait-related and state-related group differences in phonemic decoding based on local activation patterns (radius of 2.5 voxels) in the left and right ST mask. In line with the above reported approach, local searchlight results in the ST mask showed significant trait-related group difference between FRD- and FRD+ children (see Figure 4), but no state-related differences between TR and DR. Group differences between FRD+ and FRD- children for phonemic decoding were both observed in the left and right as well as in anterior and more posterior regions within the ST mask.

\section{DISCUSSION}

The longstanding believe that dyslexia is rooted in poorly specified phoneme representations was challenged by Boets et al. (2013) who demonstrated via multivariate fMRI analyses that dyslexic adults may not display a representational deficit but rather have problems in accessing these representations, as suggested by decreased fronto-temporal connectivity. This result provoked a debate, but no conclusive answer could be given on whether phonemic representations in dyslexia are intact throughout reading development, or whether there is instead a representational deficit at a younger age when well defined phonemic representations are most crucial to learning to read (Boets, 2014; Peterson \& Pennington, 2015). Our study is the first to examine clusters of activity specific to phoneme categories at a pre-diagnostic age of dyslexia. We observed in the bilateral superior temporal cortex distinct fMRI response patterns for phoneme categories in children with a low family risk, whereas children with a high family risk failed to show this distinction. Furthermore, since typical and dyslexic readers did not differ from each other, our results suggest that a representational deficit especially relates to having a family risk for dyslexia (i.e. trait-related) and less to having a reading deficit (i.e. state-related).

The differences between our current results in children versus our previous findings in adults (Boets et al., 2013) using similar neuroimaging analysis techniques, indicates that findings on phonemic representations observed in adults (with dyslexia) cannot be simply projected to children. This is in line with other studies showing that auditory cortical processing of phonemes follows a protracted development up to adolescence (Bonte, Ley, Scharke, \& Formisano, 2016; Pang \& Taylor, 2000; Sharma, Kraus, Mcgee, \& Nicol, 1997; Sowell et al., 2002). In addition, it has been demonstrated that learning to read induces changes in the speech perception network (Dehaene et al., 2010), and, of specific importance, in the neural representations of phonemes, at least temporarily, as evidenced by reading-induced shifts in the neural representations of ambiguous speech sounds (Bonte et al., 2017). Therefore, investigating the role of phonemic representations in dyslexia should happen early in reading development, when these representations have not yet been impacted by the amount and the efficiency of reading. This also co-occurs with the moment that phonemic representations matter most, that is when a child learns how to couple phoneme representations to the corresponding graphemes. Our study is the first to examine neural 
phonemic representations at this early stage of reading and for phonemic contrasts, such as stop consonants, for which difficulties in categorizing have repeatedly been shown in dyslexia (for a metaanalysis see Noordenbos \& Serniclaes, 2015).

We were able to discriminate activation patterns for different stop consonants in left and right temporal cortices in children with a low family risk. These distinctive neural representations for different phonemes were found despite acoustic variability within each phoneme (induced by different speakers) that was as large as the acoustic variability between phonemes. Hence, the neural distinctiveness reflects higher order-aspects of representation rather than low-level acoustic differences. Sensitivity of MVPA methods to stop consonant representations in young children is not self-evident since classification accuracy of phonemes tend to be lower in children than in adults (Bonte et al., 2016) and lower for stop consonants than vowels (Boets et al., 2013). Furthermore, the use of a passive design in this study, ensuring a higher ecological validity and no meta-linguistic influences on the outcome of the neural representations, might also have made it more difficult to clearly observe distinct neural phonemic representations. Nevertheless, tested by robust statistical permutation techniques, phonemic decoding in low family risk children was observed using both distributed (i.e. selecting 250,500 or 1,000 voxels selected based on univariate activation) and focal (i.e. searchlight based on neighbouring voxels) patterns of activation across the bilateral temporal cortex. The distributed MVPA approach has the advantage that the exact set of voxels selected for analysis can differ between subjects, allowing to take into account inter-individual variability (for a review see Price, Hope, \& Seghier, 2017). An interesting result that we observed is that decoding improved when voxels were selected from both the left and right hemisphere (relative to restricting the selection to one hemisphere with the same amount of voxels). Given that the amount of voxels was the same in unilateral and bilateral selections, improved bilateral performance cannot be explained by more multivariate power. Rather, it seems to indicate that phonemic representations and speech perceptions build on bilateral neural information in beginning readers. This is in line with phoneme decoding results in adults (e.g. Bonte et al., 2014; Formisano et al., 2008; Kilian-Hutten et al., 2011), but contrasts with the traditional view that phonemic processing predominantly relies on left hemispheric auditory/language regions. A presumed left-hemispheric bias for phonemic processing is typically linked to reports of a same bias for temporal auditory analysis, which is important for phoneme perception (Obleser, Eisner, \& Kotz, 2008; Zatorre \& Belin, 2001). However, this signal-driven explanation of a left dominance for phonemic rate processing has been criticized (Scott \& McGettigan, 2013) and recent evidence suggests a posterior to anterior superior temporal gradient for the processing fast versus slow temporal modulations rather than the often assumed left versus right hemispheric differences (Hullett, Hamilton, Mesgarani, Schreiner, \& Chang, 2016; Santoro et al., 2014). Nevertheless, a stronger left hemispheric bias for phoneme processing may emerge throughout development by interacting with learning mechanisms that predominantly rely on the left hemisphere (Minagawa-Kawai, Cristià, \& Dupoux, 2011). A bilateral involvement early in development, followed by an increasing specialization of the left hemisphere after school entry, has also been suggested for the reading network. More specifically, crosssectional studies (Shaywitz et al., 2002; Turkeltaub, Gareau, Flowers, Zeffiro, \& Eden, 2003) have suggested that right hemispheric regions are recruited during the early stage of literacy development and are later disengaged, eventually resulting in a left lateralized matured reading network.

With regard to dyslexia-related difficulties in forming robust neural phonemic representations, we observed decreased phonemic decoding in children with a high family risk. Since children with a high family risk more often develop dyslexia and show poorer performance on literacy and phonological tasks, our results argue for a central role of phoneme representations in explaining dyslexia. However, we additionally observed that the capacity of the brain to decode phoneme representations did not significantly distinguish children who were later diagnosed with dyslexia from those who continued to show typical reading development. This suggests that less distinct neural representations of phonemes are trait (i.e. family-risk) rather than state (i.e. reading deficit) related. In other words, neural phonemic decoding - at the level of detail investigated in the current study - might not be a very sensitive and/or specific measure for the early detection of later reading problems. This finding does however provide interesting directions for further studies on the mediating role of neural phoneme representations for reading problems, the genotype of dyslexia and the potential neural compensational mechanisms to overcome reading problems despite being at risk.

Concerning a potential mediating role for reading problems (Bishop, 2013), our results demonstrate that neural representations of phonemes alone cannot explain the emergence of reading problems. The absence of a sole neural mediator would be compatible with the multiple deficit theory (Pennington, 2006), which states that multiple cognitive and neural factors, called endophenotypic factors, mediate the environmental and genetic influences on reading ability. The key question is whether or not neural representations of phonemes can be considered as one of the endophenotypic factors mediating the phenotype of dyslexia. One potential answer is that neural phonemic representations do not play a causal role in dyslexia but are just epiphenomena with perhaps the same genetic basis as reading problems (Bishop, 2013). However, from a theoretical point of view, this seems unlikely since learning to read relies on coupling graphemes to phoneme representations. Another, more probable, explanation is that a deficit in neural phonemic representations is, at least in the children with a family risk, one of the risk factors that interacts with other risk and protective factors and the combination of them determines whether or not a child displays reading problems (Bishop, 2013; Pennington, 2006). Hence, although deficient neural representations might be a risk factor in family risk children with and without dyslexia, differences in protective factors determine whether or not reading problems are expressed. At the neural level, a potential protective factor often suggested in dyslexia research is a stronger reliance on the right hemisphere, more specifically on 
the right counterparts of the posterior reading regions (Hoeft et al., 2011; Waldie, Haigh, Badzakova-Trajkov, Buckley, \& Kirk, 2013; Xu, Yang, Siok, \& Tan, 2015) as well as on right parietal-frontal regions involved in higher order cognitive functions (Finn et al., 2014; Richards \& Berninger, 2008; Schurz et al., 2015; Žarić et al., 2017). Our study, which focused on auditory cortical processing of phonemes, suggests that typical readers with a family risk did not compensate their phonemic decoding deficit in the left auditory cortex by better decoding in the right hemisphere, since deficits were observed bilaterally. Interestingly, an investigation of the white matter tracts in largely the same sample (Vanderauwera et al., 2017; Vandermosten et al., 2015) reported the opposite pattern of state rather than trait dependent group differences for the dorsal connection from temporal to frontal regions, via the arcuate fasciculus. Namely, the arcuate fasciculus, which has a central role in further processing/manipulating phonemic representations, differed between reading groups at a pre-reading age but not between family risk groups. In addition, in our study (see Table S1.2), family risk children who developed typical reading (despite their decreased phonemic decoding) scored significantly higher on vocabulary than typical readers without a family risk $(t(32)=-2.17, p=0.037)$, indicating a relative strength in ora language skills. We therefore hypothesize that ventral white matter tracts, which typically sustain semantic skills such as vocabulary (Dick \& Tremblay, 2012; Saur \& Hartwigsen, 2012), together with dorsal white matter tracts can act as potential protective mechanisms to compensate for the local deficits family risk children display in the temporal lobe.

Our findings might provide a foundation for future studies that could shed new light on the genotype of dyslexia. Although we should be extremely careful with interpreting differences between our four subgroups (given the low number of dyslexic readers with a low family risk), our data suggest that only dyslexic readers with a high family risk are affected by decreased phonemic representations but not the dyslexic readers with a low family risk (see Data S1). In line with what has been suggested in autism research (O'Roak et al., 2014), reading problems in dyslexic readers with a low family risk could be driven by non-genetic influences or by de novo mutations in the genes, whereas shared genes drive reading problems in dyslexic readers with a high family risk. This might imply that dyslexics with a low versus high family risk differ in terms of severity of the genetic deficit as well as on which specific genes are impaired. Taking into account the multidimensional view on dyslexia (Pennington, 2006), it is not unconceivable that, if a different genetic basis indeed existed for dyslexic children with a low versus high family risk, this might differentially impact their neurobehavioural profile, implying different neural and/or behavioural predictors of reading outcome. Previous longitudinal dyslexia studies, mainly included dyslexic children with a high family risk, and in these studies familial influences are very apparent in the way infants and preschoolers process speech and auditory sounds (for a review see Ozernov-Palchik \& Gaab, 2016). It may even be the case that these early differences between the family risk groups are larger than differences between reading level groups (Hakvoort et al., 2015), with similar patterns found for the structure of the planum temporale (Vanderauwera, Altarelli, Vandermosten, Wouters, et al., 2018). Note, however, that we cannot exclude that dyslexia (i.e. state) related group differences could have been found if another paradigm or a younger age group was tested. It has for example been suggested that testing allophonic processing, by using speech continua or foreign speech sounds (as used in the MVPA experiment of Lee et al., 2012; Raizada et al., 2010), may be more sensitive to detect dyslexia-related deficits than testing categorical phoneme representations (Serniclaes \& Seck, 2018). Although we believe that our stimuli had sufficient within-phoneme acoustic variance to target decreased allophonic sensitivity in children with dyslexia, future fMRI decoding studies that tap more directly on allophonic perception are important to validate our results of trait but not state related differences in phonemic representations. In addition, since we tested grade 2 children, the importance of phonemic representations might have already decreased since in grade 2 the grapheme-phoneme reading strategy starts to be complemented by a direct orthographic reading strategy. Therefore, studies in pre-readers and grade 1 readers would be needed to provide more insight in this.

To conclude, we observed that beginning readers with a low family risk showed distinct neural phonemic representations that could be distinguished within superior temporal activation patterns. More specifically, the activation patterns of speech sounds belonging to the same phonemes were more alike than of speech sounds belonging to different phonemes, despite the acoustic variability between all the speech sounds. Second, we observed that beginning readers with a family risk show less specified phonemic representations than the low family risk children. However, no group differences in neural representations were found for children that were retrospectively classified as typical or dyslexic readers. This indicates that less specified phonemic neural representations are a risk factor for dyslexia, but in order to develop dyslexia, an interaction with other affected neural systems, such as a less developed fronto-temporal connection, is presumably necessary.

\section{ACKNOWLEDGEMENTS}

All participants, parents, teachers and schools that participated in this study are gratefully acknowledged. We would like to thank Astrid De Vos, Sophie Vanvooren, Frauke Moerenhout and Lieselore Cuynen for participant selection and data collection. We thank Bart Boets for fruitful discussion on the adult experiment that was the starting point for the current study. We are also grateful to Ron Peeters for technical MRI support. Jolijn Vanderauwera is postdoctoral fellow of the Research Foundation Flanders. This research was funded by the Research Council of KU Leuven (OT/12/044), the Research Foundation Flanders (G0920.12), postdoctoral grant of Maaike Vandermosten (Research Foundation Flanders) and the Netherlands Organization for Scientific Research (Vidi-Grant 452-16-004 to Milene Bonte). 


\section{CONFLICT OF INTEREST}

The authors have no conflict of interest to declare.

\section{DATA AVAILABILITY STATEMENT}

Data have not been shared in a data repository but can be shared on personal request (if in line with medical ethical consent of the participants). For data sharing please contact Maaike Vandermosten.

\section{REFERENCES}

American Psychiatric Association. (2013). Diagnostic and statistical manual of mental disorders. Washington, DC: American Psychiatric Association.

Bishop, D. V. M. (2013). Cerebral asymmetry and language development: Cause, correlate or consequence? Why are some children poor at language learning? Science, 340(6138), 1230531-1230531. https:// doi.org/10.1126/science.1230531

Blau, V., Reithler, J., van Atteveldt, N., Seitz, J., Gerretsen, P., Goebel, R., \& Blomert, L. (2010). Deviant processing of letters and speech sounds as proximate cause of reading failure: $A$ functional magnetic resonance imaging study of dyslexic children. Brain, 133(3), 868-879. https://doi.org/10.1093/brain/awp308.

Blau, V., van Atteveldt, N., Ekkebus, M., Goebel, R., \& Blomert, L. (2009). Reduced neural integration of letters and speech sounds links phonological and reading deficits in adult dyslexia. Current Biology, 19(6), 503-508. https://doi.org/10.1016/j.cub.2009.01.065.

Boada, R., \& Pennington, B. F. (2006). Deficient implicit phonological representations in children with dyslexia. Journal of Experimental Child Psychology, 95(3), 153-193. https://doi.org/10.1016/j. jecp.2006.04.003

Boets, B. (2014). Dyslexia: Reconciling controversies within an integrative developmental perspective. Trends in Cognitive Sciences, 18(10), 501-503. https://doi.org/10.1016/j.tics.2014.06.003

Boets, B., Op de Beeck, H. P., Vandermosten, M., Scott, S. K., Gillebert, C. R., Mantini, D., ... Ghesquiere, P. (2013). Intact but less accessible phonetic representations in adults with dyslexia. Science (New York, N.Y.), 342(6163), 1251-1254. https://doi.org/10.1126/scien ce. 1244333

Boets, B., Vandermosten, M., Poelmans, H., Luts, H., Wouters, J., \& Ghesquière, P. (2011). Preschool impairments in auditory processing and speech perception uniquely predict future reading problems. Research in Developmental Disabilities, 32(2), 560-570. https://doi. org/10.1016/j.ridd.2010.12.020

Boetsch, E. A., Green, P. A., \& Pennington, B. F. (1996). Psychosocial correlates of dyslexia across the life span. Development and Psychopathology, 8(3), 539. https://doi.org/10.1017/S095457940 0007264

Bonte, M. L., \& Blomert, L. (2004). Developmental dyslexia: ERP correlates of anomalous phonological processing during spoken word recognition. Cognitive Brain Research, 21(3), 360-376. https://doi. org/10.1016/J.COGBRAINRES.2004.06.010

Bonte, M., Correia, J. M., Keetels, M., Vroomen, J., \& Formisano, E. (2017). Reading-induced shifts of perceptual speech representations in auditory cortex. Scientific Reports, 7(1), 1-11. https://doi.org/10.1038/ s41598-017-05356-3

Bonte, M., Hausfeld, L., Scharke, W., Valente, G., \& Formisano, E. (2014). Task-dependent decoding of speaker and vowel identity from auditory cortical response patterns. Journal of Neuroscience, 34(13), 4548-4557. https://doi.org/10.1523/JNEUROSCI.4339-13.2014

Bonte, M., Ley, A., Scharke, W., \& Formisano, E. (2016). Developmental refinement of cortical systems for speech and voice processing.
Neurolmage, 128, 373-384. https://doi.org/10.1016/J.NEURO IMAGE.2016.01.015

Bonte, M. L., Poelmans, H., \& Blomert, L. (2007). Deviant neurophysiological responses to phonological regularities in speech in dyslexic children. Neuropsychologia, 45(7), 1427-1437. https://doi.org/10.1016/j. neuropsychologia.2006.11.009

Brus, B. T., \& Voeten, M. J. (1973). Eén Minuut Test: Verantwoording en handleiding [One Minute Test: Manual]. Amsterdam, Netherlands: Harcourt Test Publishers

Bus, A. G., \& Van ljzendoorn, M. H. (1999). Phonological awareness and early reading: A meta-analysis of experimental training studies. Journal of Educational Psychology, 91(3), 403-414. https://doi. org/10.1037/0022-0663.91.3.403

Chomsky, N., \& Halle, M. (1968). The sound of pattern of english. New York, NY: Harper \& Row.

Dehaene, S., Pegado, F., Braga, L. W., Ventura, P., Filho, G. N., Jobert, A., ... Cohen, L. (2010). How learning to read changes the cortical networks for vision and language. Science, 330(6009), 1359-1364. https ://doi.org/10.1126/science.1194140

Dickie, C., Ota, M., \& Clark, A. (2013). Revisiting the phonological deficit in dyslexia: Are implicit nonorthographic representations impaired? Applied Psycholinguistics, 34(4), 649-672. https://doi.org/10.1017/ S0142716411000907.

Dick, A. S., \& Tremblay, P. (2012). Beyond the arcuate fasciculus: Consensus and controversy in the connectional anatomy of language. Brain, 135(12), 3529-3550. https://doi.org/10.1093/brain/aws222

Diehl, R. L. (2008). Acoustic and auditory phonetics: The adaptive design of speech sound systems. Philosophical Transactions of the Royal Society of London. Series B, Biological Sciences, 363(1493), 965-978. https://doi.org/10.1098/rstb.2007.2153

Dudal, P. (1997). Leerlingvolgsysteem VCLB (CSBO). Spelling: Toetsen 1-2-3. Basisboek en kopieerbundel [Student trajectory system. Spelling: Grade 1-2-3. Manual. Leuven, Belgium: Garant.

Finn, E. S., Shen, X., Holahan, J. M., Scheinost, D., Lacadie, C., Papademetris, X., ... Constable, R. T. (2014). Disruption of functional networks in dyslexia: A whole-brain, data-driven analysis of connectivity. Biological Psychiatry, 76(5), 397-404. https://doi.org/10.1016/j. biopsych.2013.08.031

Formisano, E., De Martino, F., Bonte, M., \& Goebel, R. (2008). "Who" is saying "what" Brain-based decoding of human voice and speech. Science (New York, N.Y.), 322(5903), 970-973. https://doi. org/10.1126/science.1164318

Gabay, Y., \& Holt, L. L. (2015). Incidental learning of sound categories is impaired in developmental dyslexia. Cortex, 73, 131-143. https://doi. org/10.1016/j.cortex.2015.08.008

Goebel, R. (2012). BrainVoyager - Past, present, future. Neurolmage, 62(2), 748-756. https://doi.org/10.1016/j.neuroimage.2012.01.083

Goebel, R., Esposito, F., \& Formisano, E. (2006). Analysis of functional image analysis contest (FIAC) data with brainvoyager QX: From single-subject to cortically aligned group general linear model analysis and self-organizing group independent component analysis. Human Brain Mapping, 27(5), 392-401. https://doi.org/10.1002/hbm.20249

Goswami, U., Power, A. J., Lallier, M., \& Facoetti, A. (2014). Oscillatory "temporal sampling" and developmental dyslexia: Toward an overarching theoretical framework. Frontiers in Human Neuroscience, 8, 904. https://doi.org/10.3389/fnhum.2014.00904

Guttorm, T. K., Leppänen, P. H. T., Richardson, U., \& Lyytinen, H. (2001). Event-Related potentials and consonant differentiation in newborns with familial fisk for dyslexia. Journal of Learning Disabilities, 34(6), 534-544. https://doi.org/10.1177/002221940103400606.

Guttorm, T. K., Leppänen, P. H. T., Tolvanen, A., \& Lyytinen, H. (2003). Event-related potentials in newborns with and without familial risk for dyslexia: Principal component analysis reveals differences between the groups. Journal of Neural Transmission, 110, 1059-1074. https://doi.org/10.1007/s00702-003-0014-x 
Hakvoort, B., Van Der Leij, A., Maurits, N., Maassen, B., \& Van Zuijen, T. L. (2015). Basic auditory processing is related to familial risk, not to reading fluency: An ERP study. Cortex; A Journal Devoted to the Study of the Nervous System and Behavior, 63, 90-103. https://doi. org/10.1016/j.cortex.2014.08.013

Hämäläinen, J. A., Salminen, H. K., \& Leppänen, P. H. T. (2012). Basic auditory processing deficits in dyslexia: Systematic review of the behavioral and event-related potential/ field evidence. Journal of Learning Disabilities, 46(5), 413-427. https://doi.org/10.1177/00222 19411436213

Haxby, J. V, Gobbini, M. I., Furey, M. L., Ishai, A., Schouten, J. L., \& Pietrini, P. (2001). Distributed and overlapping representations of faces and objects in ventral temporal cortex. Science (New York, N.Y.), 293(5539), 2425-2430. https://doi.org/10.1126/science.1063736

Hendren, R. L., Haft, S. L., Black, J. M., White, N. C., \& Hoeft, F. (2018). Recognizing psychiatric comorbidity with reading disorders. Frontiers in Psychiatry, 9, 101. https://doi.org/10.3389/fpsyt.2018.00101

Hoeft, F., McCandliss, B. D., Black, J. M., Gantman, A., Zakerani, N., Hulme, C., ... Gabrieli, J. D. E. (2011). Neural systems predicting long-term outcome in dyslexia. Proceedings of the National Academy of Sciences, 108(1), 361-366. https://doi.org/10.1073/pnas.10089 50108

Hong, D. S. (2014). Learning disorders and ADHD: Are LDs getting the attention they deserve? Journal of the American Academy of Child \& Adolescent Psychiatry, 53(9), 933-934. https://doi.org/10.1016/J. JAAC.2014.06.006

Hornickel, J., Chandrasekaran, B., Zecker, S., \& Kraus, N. (2011). Auditory brainstem measures predict reading and speech-in-noise perception in school-aged children. Behavioural Brain Research, 216(2), 597-605. https://doi.org/10.1016/j.bbr.2010.08.051.

Hornickel, J., \& Kraus, N. (2013). Unstable Representation of Sound: A Biological Marker of Dyslexia. Journal of Neuroscience, 33(8), 35003504. https://doi.org/10.1523/JNEUROSCI.4205-12.2013.

Hornickel, J., Skoe, E., Nicol, T., Zecker, S., \& Kraus, N. (2009). Subcortical differentiation of stop consonants relates to reading and speech-innoise perception. Proceedings of the National Academy of Sciences, 106(31), 13022-13027. https://doi.org/10.1073/pnas.0901123106.

Hullett, P. W., Hamilton, L. S., Mesgarani, N., Schreiner, C. E., \& Chang, E. F. (2016). Human superior temporal gyrus organization of spectrotemporal modulation tuning derived from speech stimuli. Journal of Neuroscience, 36(6), 2014-2026. https://doi.org/10.1523/JNEUR OSCI.1779-15.2016

Kilian-Hutten, N., Valente, G., Vroomen, J., \& Formisano, E. (2011). Auditory cortex encodes the perceptual interpretation of ambiguous sound. Journal of Neuroscience, 31(5), 1715-1720. https://doi. org/10.1523/JNEUROSCI.4572-10.2011

Information-based functional brain mapping. Proceedings of the National Academy of Sciences, 103(10), 3863-3868. https://doi.org/10.1073/ pnas.0600244103

Kuhl, P. K. (2004). Early language acquisition: Cracking the speech code. Nature Reviews Neuroscience, 5(11), 831-843. https://doi. org/10.1038/nrn1533

Lee, Y.-S., Turkeltaub, P., Granger, R., \& Raizada, R. D. S. (2012). Categorical speech processing in Broca's area: An fMRI study using multivariate pattern-based analysis. Journal of Neuroscience, 32(11), 3942-3948. https://doi.org/10.1523/JNEUROSCI.3814-11.2012

Matsala, J. L. (1997). Spoken word recognition in reading disabled children. Journal of Educational Psychology, 89(1), 159-169. https://doi. org/10.1037/0022-0663.89.1.159

Maye, J., Werker, J. F., \& Gerken, L. A. (2002). Infant sensitivity to distributional information can affect phonetic discrimination. Cognition, 82(3), B101-B111.https://doi.org/10.1016/S0010-0277(01)00157-3

Melby-Lervåg, M., \& Lervåg, A. (2012). Oral language skills moderate nonword repetition skills in children with dyslexia: A meta-analysis of the role of nonword repetition skills in dyslexia. Scientific
Studies of Reading, 16(1), 1-34. https://doi.org/10.1080/10888 438.2010.537715

Melby-Lervåg, M., Lyster, S.-A.-H., \& Hulme, C. (2012). Phonological skills and their role in learning to read: A meta-analytic review. Psychological Bulletin, 138(2), 322-352. https://doi.org/10.1037/ a0026744

Minagawa-Kawai, Y., Cristià, A., \& Dupoux, E. (2011). Cerebral lateralization and early speech acquisition: A developmental scenario. Developmental Cognitive Neuroscience, 1(3), 217-232. https://doi. org/10.1016/j.dcn.2011.03.005

Molfese, D. L. (2000). Predicting Dyslexia at 8 Years of Age Using Neonatal Brain Responses. Brain and Language, 72(3), 238-245. https ://doi.org/10.1006/brln.2000.2287.

Monzalvo, K., Fluss, J., Billard, C., Dehaene, S., \& Dehaene-Lambertz, G. (2012). Cortical networks for vision and language in dyslexic and normal children of variable socio-economic status. Neurolmage, 61(1), 258-274. https://doi.org/10.1016/j.neuro image.2012.02.035.

Moore, B. C. J. (2008). Basic auditory processes involved in the analysis of speech sounds. Philosophical Transactions of the Royal Society of London. Series B, Biological Sciences, 363(1493), 947-963. https://doi. org/10.1098/rstb.2007.2152

Nichols, T. E., \& Holmes, A. P. (2001). Nonparametric permutation tests for functional neuroimaging: A primer with examples. Human Brain Mapping, 15(1), 1-25. https://doi.org/10.1002/hbm.1058

Noordenbos, M. W., Segers, E., Serniclaes, W., Mitterer, H., \& Verhoeven, L. (2012). Neural evidence of allophonic perception in children at risk for dyslexia. Neuropsychologia, 50(8), 2010-2017. https://doi. org/10.1016/j.neuropsychologia.2012.04.026

Noordenbos, M. W., \& Serniclaes, W. (2015). The categorical perception deficit in dyslexia: A meta-analysis. Scientific Studies of Reading, 19(5), 340-359. https://doi.org/10.1080/10888438.2015.1052455

Obleser, J., Eisner, F., \& Kotz, S. A. (2008). Bilateral speech comprehension reflects differential sensitivity to spectral and temporal features. The Journal of Neuroscience, 28(32), 8116-8124. https://doi. org/10.1523/JNEUROSCI.1290-08.2008

O'Roak, B. J., Stessman, H. A., Boyle, E. A., Witherspoon, K. T., Martin, B., Lee, C., ... Eichler, E. E. (2014). Recurrent de novo mutations implicate novel genes underlying simplex autism risk. Nature Communications, 5, 5595. https://doi.org/10.1038/ncomms6595

Ozernov-Palchik, O., \& Gaab, N. (2016). Tackling the "dyslexia paradox": Reading brain and behavior for early markers of developmental dyslexia. Wires Cognitive Science, 7, 156-176. https://doi.org/10.1002/ wcs.1383

Pang, E. W., \& Taylor, M. J. (2000). Tracking the development of the N1 from age 3 to adulthood: An examination of speech and nonspeech stimuli. Clinical Neurophysiology, 111, 388-397. https://doi. org/10.1016/S1388-2457(99)00259-X

Pennington, B. F. (2006). From single to multiple deficit models of developmental disorders. Cognition, 101(2), 385-413. https://doi. org/10.1016/j.cognition.2006.04.008

Peterson, R. L., \& Pennington, B. F. (2015). Developmental dyslexia. Annual Review of Clinical Psychology, 11(1), 283-307. https://doi. org/10.1146/annurev-clinpsy-032814-112842

Price, C. J., Hope, T. M., \& Seghier, M. L. (2017). Ten problems and solutions when predicting individual outcome from lesion site after stroke. Neurolmage, 145, 200-208. https://doi.org/10.1016/j.neuro image.2016.08.006

Raizada, R. D. S., Tsao, F.-M., Liu, H.-M., Holloway, I. D., Ansari, D., \& Kuhl, P. K. (2010). Linking brain-wide multivoxel activation patterns to behaviour: Examples from language and math. Neurolmage, 51(1), 462-471. https://doi.org/10.1016/J.NEUROIMAGE.2010.01.080

Ramus, F. (2003). Theories of developmental dyslexia: Insights from a multiple case study of dyslexic adults. Brain, 126(4), 841-865. https ://doi.org/10.1093/brain/awg076 
Ramus, F., \& Szenkovits, G. (2008). What phonological deficit? The Quarterly Journal of Experimental Psychology, 61(1), 129-141. https:// doi.org/10.1080/17470210701508822

Richards, T. L., \& Berninger, V. W. (2008). Abnormal fMRI connectivity in children with dyslexia during a phoneme task: Before but not after treatment. Journal of Neurolinguistics, 21(4), 294-304. https://doi. org/10.1016/J.JNEUROLING.2007.07.002

Saksida, A., lannuzzi, S., Bogliotti, C., Chaix, Y., Démonet, J.-F., Bricout, L., ... Ramus, F. (2016). Phonological skills, visual attention span, and visual stress in developmental dyslexia. Developmental Psychology, 52(10), 1503-1516. https://doi.org/10.1037/dev0000184

Santoro, R., Moerel, M., De Martino, F., Goebel, R., Ugurbil, K., Yacoub, E., \& Formisano, E. (2014). Encoding of natural sounds at multiple spectral and temporal resolutions in the human auditory cortex. PLoS Computational Biology, 10(1), e1003412. https://doi.org/10.1371/ journal.pcbi.1003412

Saur, D., \& Hartwigsen, G. (2012). Neurobiology of language recovery after stroke: Lessons from neuroimaging studies. Archives of Physical Medicine and Rehabilitation, 93(1), S15-S25. https://doi. org/10.1016/j.apmr.2011.03.036

Schurz, M., Wimmer, H., Richlan, F., Ludersdorfer, P., Klackl, J., \& Kronbichler, M. (2015). Resting-state and task-based functional brain connectivity in developmental dyslexia. Cerebral Cortex, 25(10), 3502-3514. https://doi.org/10.1093/cercor/bhu184

Scott, S. K., \& McGettigan, C. (2013). Do temporal processes underlie left hemisphere dominance in speech perception? Brain and Language, 127(1), 36-45. https://doi.org/10.1016/j.bandl.2013.07.006

Serniclaes, W., \& Seck, M. (2018). Enhanced sensitivity to subphonemic segments in dyslexia: A new instance of allophonic perception. Brain Sciences, 8(4), 54. https://doi.org/10.3390/brainsci8040054

Shaywitz, B. A., Shaywitz, S. E., Pugh, K. R., Mencl, W. E., Fulbright, R. K., Skudlarski, P., ... Gore, J. C. (2002). Disruption of posterior brain systems for reading in children with developmental dyslexia. Biological Psychiatry, 52(2), 101-10.

Sharma, A., Kraus, N., Mcgee, T. J., \& Nicol, T. G. (1997). Developmental changes in P1 and N1 central auditory responses elicited by consonant-vowel syllables. Electroencephalography and Clinical Neurophysiology/Evoked Potentials Section, 104, 540-545. https://doi. org/10.1016/s0168-5597(97)00050-6

Snowling, M. (2000). Dyslexia. Retrieved from http://psycnet.apa.org/ psycinfo/2000-12298-000

Sowell, E. R., Thompson, P. M., Rex, D., Kornsand, D., Tessner, K. D. Jernigan, T. L., \& Toga, A. W. (2002). Mapping sulcal pattern asymmetry and local cortical surface gray matter distribution in vivo: Maturation in perisylvian cortices. Cerebral Cortex, 12(1), 17-26. https://doi.org/10.1093/cercor/12.1.17

Talairach, J., \& Tournoux, P. (1988). Co-planar Stereotaxic Atlas of the Human Brain. Stuttgart: Georg Thieme Verlag.

Theys, C., Wouters, J., \& Ghesquière, P. (2014). Diffusion tensor imaging and resting-state functional MRI-scanning in 5- and 6-year-old children: Training protocol and motion assessment. PLoS ONE, 9(4), e94019. https://doi.org/10.1371/journal.pone.0094019

Torgesen, J. K. (2000). Individual differences in response to early interventions in reading: The lingering problem of treatment resisters. Learning Disabilities Research and Practice, 15(1), 55-64. https://doi. org/10.1207/SLDRP1501_6

Torgesen, J. K. (2002). The prevention of reading difficulties. Journal of School Psychology, 40(1), 7-26. https://doi.org/10.1016/ S0022-4405(01)00092-9

Turkeltaub, P. E., Gareau, L., Flowers, D. L., Zeffiro, T. A., \& Eden, G. F. (2003). Development of neural mechanisms for reading. Nature Neuroscience, 6(7), 767-773. https://doi.org/10.1038/nn1065.

van den Bos, K. P., Spelberg, H. C. L., Scheepstra, A. J., \& de Vries, J. R. (1994). De Klepel. Vorm A en B. Een test voor leesvaardigheid van pseudowoorden. Verantwoording, handleiding, diagnostiek en behandeling [Word and non word reading test A \& B manual]. Nijmegen, Berkhout: Swets Test Publishers.

van Herten, M., Pasman, J., van Leeuwen, T.H., Been, P.H., van der Leij, A., Zwarts, F., \& Maassen, B. (2008). Differences in AERP responses and atypical hemispheric specialization in 17-month-old children at risk of dyslexia. Brain Research, 1201, 100-105. https:// doi.org/10.1016/J.BRAINRES.2008.01.060.

Vanderauwera, J., Altarelli, I., Vandermosten, M., De Vos, A., Wouters, J., \& Ghesquière, P. (2018). Atypical structural asymmetry of the planum temporale is related to family history of dyslexia. Cerebral Cortex, 28, 63-72. https://doi.org/10.1093/cercor/bhw348

Vanderauwera, J., Altarelli, I., Vandermosten, M., Wouters, J., \& Ghesquière, P. (2018). Atpical structural asymmetry of the planum temporale in relation with family history of dyslexia and reading (dis) ability. Cerebral Cortex. 28, 63-72.https://doi.org/10.1093/cercor/ bhw348

Vanderauwera, J., De Vos, A., Forkel, S. J., Catani, M., Wouters, J., Vandermosten, M., \& Ghesquière, P. (2018). Neural organization of ventral white matter tracts parallels the initial steps of reading development: A DTI tractography study. Brain and Language, 183, 32-40. https://doi.org/10.1016/j.bandl.2018.05.007

Vanderauwera, J., Wouters, J., Vandermosten, M., \& Ghesquière, P. (2017). Early dynamics of white matter deficits in children developing dyslexia. Developmental Cognitive Neuroscience, 27, 69-77. https ://doi.org/10.1016/j.den.2017.08.003

Vandermosten, M., Boets, B., Luts, H., Poelmans, H., Golestani, N., Wouters, J., \& Ghesquière, P. (2010). Adults with dyslexia are impaired in categorizing speech and nonspeech sounds on the basis of temporal cues. Proceedings of the National Academy of Sciences of the United States of America, 107(23), 10389-10394. https://doi. org/10.1073/pnas.0912858107

Vandermosten, M., Boets, B., Luts, H., Poelmans, H., Wouters, J., \& Ghesquière, P. (2011). Impairments in speech and nonspeech sound categorization in children with dyslexia are driven by temporal processing difficulties. Research in Developmental Disabilities, 32(2), 593603. https://doi.org/10.1016/j.ridd.2010.12.015

Vandermosten, M., Vanderauwera, J., Theys, C., De Vos, A., Vanvooren, S., Sunaert, S., ... Ghesquière, P. (2015). A DTI tractography study in pre-readers at risk for dyslexia. Developmental Cognitive Neuroscience, 14, 8-15. https://doi.org/10.1016/j.dcn.2015.05.006

Vandermosten, M., Wouters, J., Ghesquière, P., \& Golestani, N. (2019). Statistical Learning of Speech Sounds in Dyslexic and Typical Reading Children. Scientific Studies of Reading, 23(1), 116-127. https ://doi.org/10.1080/10888438.2018.1473404.

Vanvooren, S., Poelmans, H., Hofmann, M., Ghesquière, P., \& Wouters, J. (2014). Hemispheric Asymmetry in Auditory Processing of Speech Envelope Modulations in Prereading Children. Journal of Neuroscience, 34(4).

Vellutino, F. R., Fletcher, J. M., Snowling, M. J., \& Scanlon, D. M. (2004). Specific reading disability (dyslexia): What have we learned in the past four decades? Journal of Child Psychology and Psychiatry, 45(1), 2-40. https://doi.org/10.1046/j.0021-9630.2003.00305.x

Waldie, K. E., Haigh, C. E., Badzakova-Trajkov, G., Buckley, J., \& Kirk, I. J. (2013). Reading the wrong way with the right hemisphere. Brain Sciences, 3(3), 1060-1075. https://doi.org/10.3390/brainsci3031060

Wanzek, J., \& Vaughn, S. (2007). Research-based implications from extensive early reading interventions. School Psychology Review, 36(4), 541-561. Retrieved from http://apps.webofknowledge.com.kuleu ven.ezproxy.kuleuven.be/full_record.do?product=WOS\&search mode $=$ Gener alSearch\&qxml:id=13\&SID $=$ U1 JOMHajFPeSzhs DF6r\&page $=1 \&$ doc $=1$

Xu, M., Yang, J., Siok, W. T., \& Tan, L. H. (2015). Atypical lateralization of phonological working memory in developmental dyslexia. Journal of Neurolinguistics, 33, 67-77. https://doi.org/10.1016/J.JNEUR OLING.2014.07.004 
Žarić, G., Correia, J. M., Fraga González, G., Tijms, J., van der Molen, M. W., Blomert, L., \& Bonte, M. (2017). Altered patterns of directed connectivity within the reading network of dyslexic children and their relation to reading dysfluency. Developmental Cognitive Neuroscience, 23, 1-13. https://doi.org/10.1016/j. dcn.2016.11.003

Zatorre, R. J., \& Belin, P. (2001). Spectral and temporal processing in human auditory cortex. Cerebral Cortex, 11(10), 946-953. https://doi. org/10.1093/cercor/11.10.946

Ziegler, J. C., Pech-Georgel, C., George, F., \& Lorenzi, C. (2009). Speech-perception-in-noise deficits in dyslexia. Developmental Science, 12(5), 732-745. https://doi.org/10.1111/j.1467-7687.2009. 00817.x

\section{SUPPORTING INFORMATION}

Additional supporting information may be found online in the Supporting Information section at the end of the article.

How to cite this article: Vandermosten M, Correia J, Vanderauwera J, Wouters J, Ghesquière P, Bonte M. Brain activity patterns of phonemic representations are atypical in beginning readers with family risk for dyslexia. Dev Sci. 2020;23:e12857. https://doi.org/10.1111/desc.12857 